\title{
Life-cycle cost analysis and effectiveness comparison between catch basin inlet screens and a floating trash trap for municipal solid removal from stormwater
}

\author{
C. C. Glass \& E. Holloway \\ Department of Civil Engineering, Howard University, \\ Washington DC, USA
}

\begin{abstract}
The impetus behind this research project was to investigate the effectiveness of trash removal devices with respect to the "Total Maximum Daily Loads (TMDL) of Trash for the Anacostia River Watershed, Montgomery and Prince Georges counties, Maryland and the District of Columbia". Trash is a relatively new pollutant of concern in the world of stormwater best management practices, and this is the first trash TMDL that will be applied to an interstate watershed. The three trash removal techniques evaluated were: a Bandalong trash trap installed by Stormwater Systems, an inlet screen manufactured by Trident Solutions, and a simple inlet screen designed by Dr Charles Glass. The Trident screens collected $408 \mathrm{lbs}$ of trash at a material cost of $\$ 1,109$. Over the course of this project the Bandalong collected 6,405 lbs of trash with an installation cost of $\$ 56,170$. The screen designed by Dr Glass had a materials cost of $\$ 644$ and collected 1,109 lbs of trash. The cost of trash removed during the project life by the three devices were $\$ 0.58 / \mathrm{lb}, \$ 8.77 / \mathrm{lb}$, and $\$ 17.06 / \mathrm{lb}$ for the Glass design, Bandalong, and Trident screen, respectively. Trident screens designed to cover the entire throat would have been as effective as the Glass design, however they would remain more expensive. The Bandalong had the lowest cost per pound per catch basin when considering that it was effectively removing trash from approximately 759 catch basins in the District and an undetermined number of catch basins in Prince Georges County, MD.
\end{abstract}

Keywords: total maximum daily load, trash, municipal solid waste, stormwater. 


\section{Introduction}

Urban stormwater runoff and storm sewers degrade nearly 570,000 hectares of lakes ( $8 \%$ of the assessed lakes). Thus, urban runoff and combined sewer overflows (CSOs) represent serious water quality problems. Moreover, urban runoff is rapidly becoming a major source of non-point source pollution [1] and has been found to be a leading impairment source for surface waters and ground water. Lee et al. [2] have indicated that street solids and sewer-deposited material are major pollutants in urban runoff.

Historically, the role of catch basins has been to minimize sewer clogging by trapping coarse debris and reducing odor emanating from low-velocity sewers by providing a water seal [3]. According to Lager et al. [4], catch basins were considered marginal in performance as early as the turn of the century and their use in many municipalities may be more of a tradition than a practice based on performance. This is because catch basins had the tendency to settle in flat to mildly sloped pipes, causing clogs, backups and overflows which produced noxious odors. Unlike specially designed stormwater treatment vaults, catch basins are not intended to remove fine particles or soluble pollutants, and they may only marginally reduce concentrations of contaminants or suspended solids [5].

The urban runoff containing pollutants flows into storm sewer inlets with sumps, such as catch basins, which are effective at trapping coarse sediments and large debris including fast food containers and leaves. Results have shown that typical catch basins, with a capacity of 0.4 to $1.2 \mathrm{~m}^{3}$, have been estimated to retain $57 \%$ of the coarse solids and $17 \%$ of equivalent BOD [6]. A study in Boston, Massachusetts, found catch basins with routine cleaning could reduce solids by 60 to $70 \%$, COD by 10 to $56 \%$, and BOD by 54 to $88 \%$ [7].

In the absence of cleaning, catch basins can actually make water quality conditions worse. It has been reported that once a sump is 40 to $50 \%$ full, inflow water can begin to scour sediment and pollutants out of the sump, making the catch basin a source of pollutants [6]. Catch basins need to be cleaned when they reach 30 to $40 \%$ of their storage capacity. Moreover, when these catch basins are blocked, they can also create breeding grounds for mosquitoes that can carry the West Nile Virus thereby causing health hazards for the population. Cleaning of catch basins is important because blocked catch basins and pipes will not carry away stormwater, posing the risk that new storms would cause additional flooding. In order to prevent flooding, it is necessary to maximize the sewer line capacity and help control pollution levels.

\subsection{Total maximum daily loads for trash}

The US Environmental Protection Agency requested that the municipalities of Washington DC, Montgomery County, and Prince Georges Counties reduced the amount of trash they allow to enter the Anacostia River via the "Total Maximum Daily Loads of Trash for the Anacostia River Watershed, Montgomery and Prince George's Counties, Maryland and the District of 
Columbia". The trash TMDL, when finalized, will require the District to document its collection of 60,945 lbs of trash/year [7].

The only other municipality that can be identified to be farther along in the implementation of a trash TMDL is the city of Los Angeles and its surrounding partners. The city and county of Los Angeles have produces several technical reports with titles such as; "Final Technical Report: Best Management Practices for Implementing the Trash Total Maximum Daily Load", "Assessment of Catch Basin Inserts", and "Assessment of Catch Basin Opening Screen Covers". Although these reports have a plethora of information on various technologies, the take home message after studying all of them seems to be that a mix of technologies will have to be utilized to remove trash, and that the appropriate technology has to be placed in the appropriate location. Along with street sweeping, anti-littering enforcement, and trash receptacle placement, L.A. will focus on catch basin screens and limited installation of end of pipe devices where head loss in the system is not a problem.

The District of Columbia is served by both a Municipal Separate Storm Sewer System (MS4) and a Combined Sewer System (CSS), as shown in Figure 1, to move stormwater runoff away from the built environment quickly. During a storm event, most of the stormwater collected by these systems is discharged directly into the rivers causing human health effects as well as problems for the aquatic species present. Moreover, floatables and other debris transported to the sewer systems often cause blockages of the systems, which often lead to flooding. In order to prevent sewer blockages and improve the quality of the stormwater before reaching the sewer systems, catch basins are installed in urban locations, with the goal that pollutants will remain in the catch basins until they are cleaned periodically.

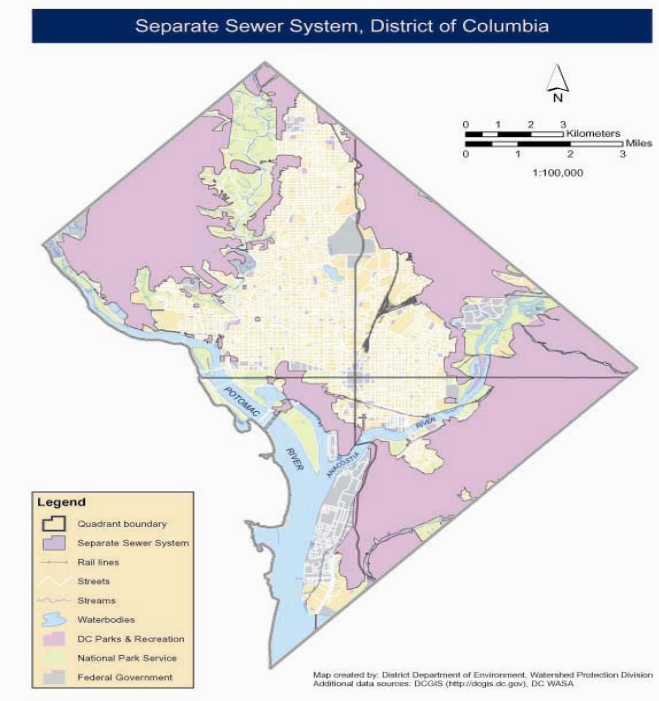

Figure 1: $\quad$ Separate sewer system in the District of Columbia. 
Catch basins are entry points for the sewer system, which are reasonably effective in protecting sewers from receiving loads of coarse solids greater than 0.04 inches $(1 \mathrm{~mm})$ in diameter and receiving waters from excessive sediment deposit [9]. Studies have shown that the removal of sediment, decaying debris, and highly polluted water by catch basins has aesthetic and water quality benefits, including reducing foul odors and reducing suspended solids [10]. The majority of the 20,000 or so catch basins in the District are simple sumps. Very little pollutant removal of any kind takes place in these simple systems, and of particular interest, no trash is held inside of these regular catch basins.

\subsection{Rational Behind Stormwater Trash Removal}

The critical issue with trash is the determination of the least expensive mechanism to keep it from reaching the Anacostia River and its tributaries. Of course the simplest solution to any problem is always the prevention of its occurrence, however the idea that citizens would stop trashing is not logical based upon the preponderance of trash in the environment. In Wards that are teaming with poverty and violence, that also maintain the highest unemployment rates in the region, convincing the population not to throw trash on the street is not a solution for what Prince Georges County Department of Environmental Resources estimates to be 20,000 tons of trash entering the Anacostia every year. Even as the Floating Debris Removal Program for the Anacostia and Potomac Rivers has removed 500 tons of trash from the Anacostia River annually, since 1992 that is only $2.5 \%$ of the estimated trash that has entered the river.

If street sweeping was implemented (which does not seem to be the case in the area of this study) and crews were available to insure that screens into catch basins do not clog with trash, the use of screens on the catch basin throats would seem to be the most cost effective solution. The use of screens would use the least expensive materials, would require the least amount of additional labor to maintain (assuming ongoing street sweeping), and would be the easiest to retrofit into the existing infrastructure. Water quality catch basins cost approximately $\$ 15,000$ to install. From an environmental justice perspective it would also leave trash where the presumed polluters live and not transport the pollution to a common resource.

Changing the design of original catch basins, those containing only a sump, is an expensive proposition. At approximately $\$ 15,000$ in cost, with the use of heavy equipment and the disturbance of the street or road during construction, regular catch basins do not get converted to water quality catch basins that can store trash and oil and grease, unless there is road reconstruction occurring. In a recent study conducted by Dr Glass evaluating four different catch basin designs the water quality catch basin dramatically outperformed the regular catch basin. Trash was not a pollutant of concern in the study, however trash was regularly removed from the water quality catch basin and never removed from the regular sump catch basin and the inlets for the two devices were directly across the street from one another. Nevertheless, the cost of replacing 20,000 catch basins at $\$ 15,000$ each does not seem feasible $(\$ 300,000,000)$. This simply does not seem like a feasible solution even though hydrodynamic catch basins have been shown 
to be effective at holding trash, while regular catch basins that contain a sump alone have been shown to be completely ineffective.

The use of catch basin inserts seems to be a reasonable solution to the problem of trash removal and depending on the equipment used, may be a viable option for removal of oil and greases that may be present intermittently, according to some product manufacturers. However, the major difficulty would be the time involved in opening manhole covers throughout the watershed and filling trash bags with all of the debris. Even with the use of vacuum trucks this would not be a feasible technology. Prior to the start of this project the team obtained evidence from Mr Dan Harper and Mr John Hollister of a study performed in Montgomery County, MD [11]. Their results showed that the sediment in street runoff dries into a hardened cake in between storms creating instantaneous bypass of the device and making them very difficult to clean. This solution would be labor intensive if selected to be implemented throughout a watershed and would require strong backs and diligence to be successful. From our experience with catch basins, it seems that they are very easy to neglect. Many catch basins seem to be ignored as long as they do not cause flooding during rain events. If managers were not diligent, randomly inspecting catch basin inserts, trash would fill up in the inserts and then overflow, defeating the purpose of their implementation. In addition, a pilot project in Montgomery County, MD found that cleaning a catch basin insert quarterly resulted in sediment and trash binding in the spaces of diamond shaped steel between cleanings. The result was bypassing of the device and inert material that was bound to the point of requiring manual cleaning (Harper and Hollister [11]).

Fifteen youths, ages 17-25, from the Earth Conservation Corps (ECC), were trained in the use, application, installation, and operation of maintenance of trash reduction technologies as part of the District's Green Collar Jobs Initiative. In this project the ECC evaluated the effectiveness of catch basin inlet screens and Bandalong. Our hypothesis is that the installation of screens, when combined with street sweeping, are the most cost and environmentally effective solutions to the problem of trashing. From an operation and maintenance perspective the Bandalong may be the most beneficial given the limited number of sites that require maintenance in contrast with the cost required for maintaining catch basin screens distributed throughout a watershed. Life cycle cost analysis tools were used to evaluate the comparative cost of each technology.

\section{Methods and materials}

Stormwater Systems installed a Bandalong Trash Trap in Watts Branch the week of April 20, 2009. Due to the amount of trash Watts Branch was selected as the site of the Bandalong and because of the location of the park surrounding it, Figure 2. The trap is 5' wide 22' overall length, with two standard collection booms, each 10' in length. The installation included a collection boom extension, approximately $30^{\prime}$ in length to make up distance from where the trap was anchored on the deep side to the opposite side on the concrete structure. The collection booms have a mesh skirt of varying lengths to accommodate changes 
in elevation (sand bar). Two aluminum fabricated rider pole assemblies were mechanically anchored to the concrete structure, and three in ground anchors to allow the trap to float from the lowest flow to the peak flow.

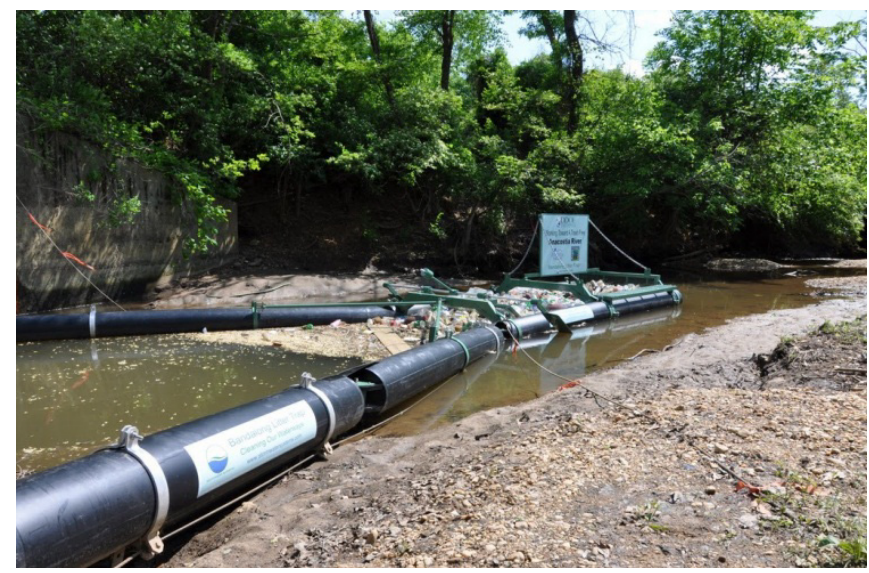

Figure 2: $\quad$ Bandalong trash trap installed on Watts branch, Washington DC.

Before installation, it was determined that trees lying in Watts Branch on the upstream side of the Dean Avenue Bridge and needed to be removed. This facilitated the installation of the Bandalong, provided access to the Bandalong, and improved its effectiveness once installed. Corps members could not remove a large log jam upstream of the Bandalong safely, and attempts to have the National Park Service (NPS) remove the jam were unsuccessful, thereby impeding the effectiveness of the Bandalong. NPS eventually removed the logs. But the in-stream positioning of the Bandalong just downstream from bridge abutments appears to protect it from large logs that could damage the device.

The Bandalong was assembled on land and lowered into Watts Branch via crane. It was then attached to the rider poles attached to the Dean Avenue Bridge. Employees of DDOE's Watershed Protection Division observed the installation process. Stormwater Systems produced a video of the Bandalong production and installation that can be viewed on You Tube (http://www.youtube.com/watch?v=9ta6SLGGTQk).

On May 12, 2009 Mayor Adrian Fenty held a press conference to unveil the Bandalong as the first such installation in North America. In attendance were the Mayor, District Department of Environment (DDOE) Director George Hawkins, Stormwater Systems, and Bandalong representatives. Corps members demonstrated for Mayor Fenty how they remove trash from the trap; after observing the log jam himself, he assisted in securing the removal of the log jam by the NPS.

The ECC Corps members attempted to inspect and clean the Bandalong at least weekly, however the frequency of the cleaning was dictated by inclement weather. Trash was manually removed, and transported back to the Henson 


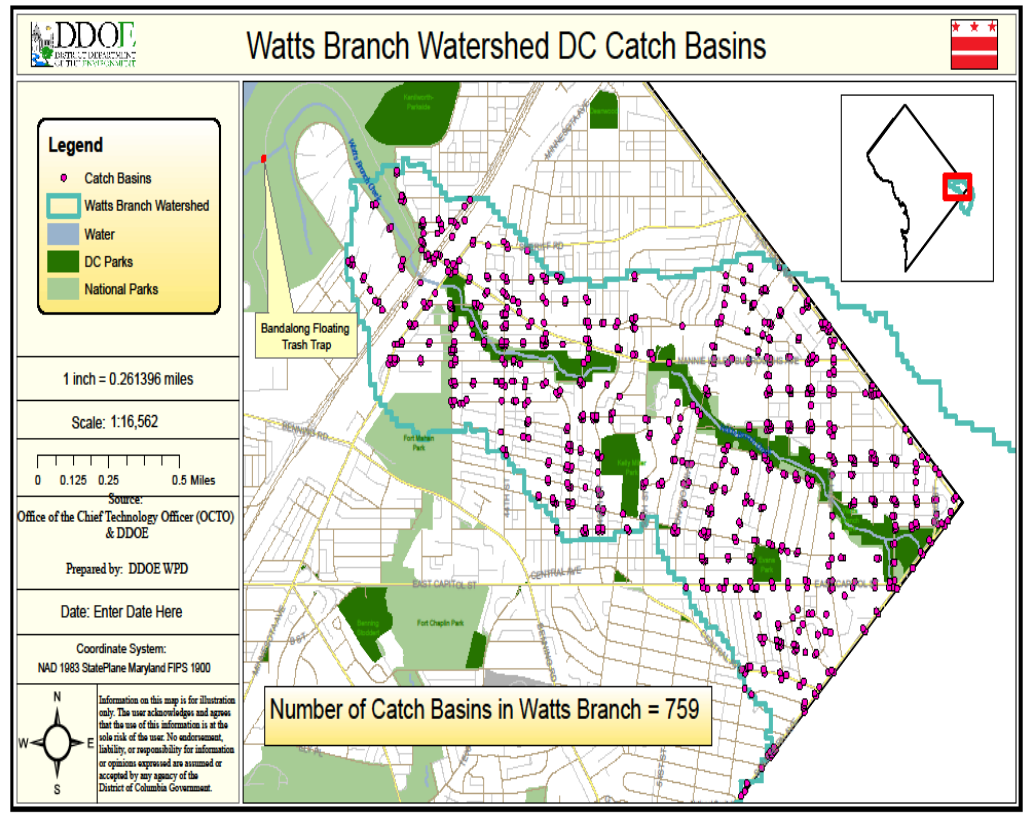

Figure 3: Watts branch watershed, Catch Basins and Bandalong locations.

Center where it was weighed and recorded. The Bandalong Data Sheet was updated each time the Bandalong was visited and cleaned.

Catch basin screen technologies were evaluated in the Fort Dupont subwatershed. This watershed was chosen because it is a relatively small storm sewer catchment area, containing approximately 50 catch basins. Dr. Charles Glass designed a catch basin inlet screen used throughout the project period. Design modifications were made when necessary to capture trash, reduce flooding, etc. In addition to the inlet screen designed by Dr. Glass, ECC also installed screens designed by Trident CurbScreens at the request of DDOE. Three ECC staff members and three Corps members were trained to build, install, and maintain catch basin inlet screens by Dr. Glass.

To install the inlet screens, the following was conducted: 1) Visited, and developed a naming system for all of the catch basins to be monitored. 2) Measured the dimensions of all of the listed catch basins. 3) Pre-cut diamond shaped steel to the appropriate dimensions for each catch basin face for the inlet screens. 4) Installed the screens using a Hammer Drill and 2 inch Redhead bolts with washers.

It was determined in the field that epoxying the diamond shaped steel screens to the cement was not effective; it took a considerable amount of time to dry and did not always hold. By using a Hammer drill and Redhead bolts to secure the screens into the cement, time was saved and the screens held up better than the Trident screens which could only be attached with the epoxy. 
By September 2009, forty-two screens had been installed out of the 50 sites. Weekly monitoring of those sites took place. The ECC Corps members documented the time and effort taken to sample each device, and the wet weight of all the trash. Special attention was paid to avoid flooding as requested by District Department of Transportation, to ensure that no vehicle accidents occurred as a result of ponding created by the screens. The majority of the screens remained in place throughout the project; however several screens had to be replaced due to vandalism and problems with the adhesive epoxy. All of the screens manufactured by Trident were utilized, but because of the varying lengths of the throat of the catch basins only 14 catch basins were covered with Trident CurbScreens.

\subsection{Life-cycle cost analysis}

In attempting to analyze the performance of Trident curbscreens, screens designed by Dr. Glass with wholesale materials, and the Bandalong, the cost of materials, installation, maintenance, and of staff and travel to and from the sites in an attempt to determine a whole-life cost for each alternative were compared. The goal was to determine the cost, over the 16 month period of evaluation, of each pound of trash removed from each device. If street sweeping would have occurred in the watersheds served by these devices the theory would be that the costs of maintaining these devices would have been lower.

\section{Results and discussion}

To begin a life cycle cost analysis an itemized list of materials, supplies, and contractors costs associated with the three devices were evaluated. All of the devices were maintained by the Corps Members and staff from the ECC, and approximately the same amount of time was required to maintain all of the catch basins (approximately 2 hours) as it did to maintain the one Bandalong. Generally, a three person crew was needed to perform cleaning of the screens or cleaning of the Bandalong, a manager and two Corps members; however the tasks of maintaining the devices can be performed with as few as two trained workers.

Expansion of the use of these devices city-wide would present a different time sink for operation and maintenance costs. Placement of an estimated 15 Bandalongs in all of the tributaries in the District would result in a cost of 450 person hours per week to maintain (assuming two hours for a three person crew to maintain each device each week). The maintenance of 20,000 screens throughout the city would take 2,400 person hours per week (assuming two hours for a three person crew to maintain 50 screens with hand cleaning). In the portions of the city that are already receiving street cleaning a reduction in the maintenance time for screen cleaning should result, however the reduction would not change the increased cost of maintaining 20,000 catch basin screens in comparison with 15 Bandalongs. The difference would result in the need to manage 20 three-person crews for the maintenance of catch basin screens, while 
only managing 4 crews for the maintenance of the Bandalongs. Of course, this is based on the desire to maintain the devices weekly. If a lower frequency of maintenance was acceptable screens may be more palatable as an option. Nevertheless the difference in maintenance requirements when contemplating expansion to a citywide program it is clear that Bandalongs would require less cost to maintain.

The Bandalong was purchased and installed for $\$ 56,170$. Other than some miscellaneous supplies, there were no other costs incurred in the installation of the Bandalong. The Trident screens were purchased for $\$ 120$ per 4 foot section. Unfortunately only catch basins of newer construction in the Fort Dupont watershed have standard 4 foot throats. Even so, each catch basin of newer construction has either two or three throat openings, generating a cost of \$240 or $\$ 360$ per catch basin retrofitted with a Trident screen. The package that the Trident screens were delivered with included L-shaped brackets that were cemented to the concrete edges of the catch basins. For longer catch basins the L-shaped bracket was cemented to the bottom of the throat. For these nonstandard length catch basins the force created when trash, sediment, and other materials were pushed against the screen caused several of the screens to require repeated installation. The standard length basins were very sturdy and withstood the pressure of water flowing into the devices with debris enmeshed in the screens.

For the Glass screen design $4 \mathrm{ft}$. by $8 \mathrm{ft}$. sections of diamond shaped steel were purchased wholesale for $\$ 65$ a sheet. From each sheet 4 to 5 catch basin screens could be cut based on the 4 to 5 inch height of each catch basin throat in the watershed. This resulted in an approximate cost of steel for each catch basin equal to $\$ 16$. Other costs included Redhead bolts with a washer $(\$ 3 /$ catch basin), masonry drill bits ( $\$ 2 /$ catch basin), plastic straps for catch basins longer than 96 inches (8 ft.) in length ( $\$ 1 /$ catch basin), and the steel cutting blade used in the circular saw, which usually lasted for several cuts $(\$ 1 /$ catch basin). This resulted in a cost of $\$ 23$ per catch basin using the Glass design and wholesale materials. It is worth noting here that incorporating this work as a part of a workforce development program is a way to do job training, but also save on labor cost for environmental technology implementation. For the 28 catch basins using the Glass design this resulted in a total material cost of $\$ 644$.

The 16 Trident screens collected $408 \mathrm{lb}$ of trash at a material cost of $\$ 1,109$. Over the course of this project the Bandalong collected 6,405 lb of trash with an installation cost of $\$ 56,170$. The 28 screens designed by Dr. Glass had a materials cost of $\$ 644$ and collected 1,109 lb of trash. The cost of trash removed during the project life by the three devices were $\$ 0.58 / \mathrm{lb}, \$ 8.77 / \mathrm{lb}$, and $\$ 17.06 / \mathrm{lb}$ for the Glass design, Bandalong, and Trident screen, respectively. The effectiveness of the Glass design was increased by the fact that the entire throat of the catch basins were covered, while the Trident screens were only designed to cover half of the throat for fear of flooding. Trident screens designed to cover the entire throat would have been as effective as the Glass design, however that would not change the higher cost for the same performance. The Bandalong had the lowest cost per $\mathrm{lb}$ per catch basin when considering that it was effectively 
being served by approximately 759 catch basins in the District and an undetermined number of catch basins in Prince Georges County, MD.

The efficiency of the three devices varied greatly based on the pounds of trash removed per catch basin served. The Glass designed screens were secured to 28 catch basins that removed $1,109 \mathrm{lb}$ of debris for an efficiency of $40 \mathrm{lb} / \mathrm{catch}$ basin. For the 16 Trident screens an efficiency of $26 \mathrm{lb} / \mathrm{catch}$ basins was calculated. The Bandalong was serving 759 catch basins from the District alone, yielding an approximate debris removal of $9 \mathrm{lb} / \mathrm{catch}$ basin. This value would be lower if all of the catch basins in the watershed were included in this calculation.

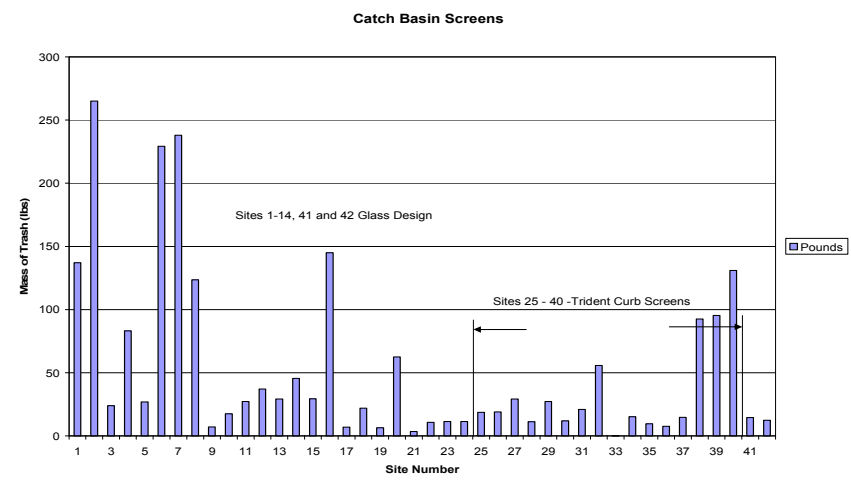

Figure 4: Total weights for each catch basin screen.

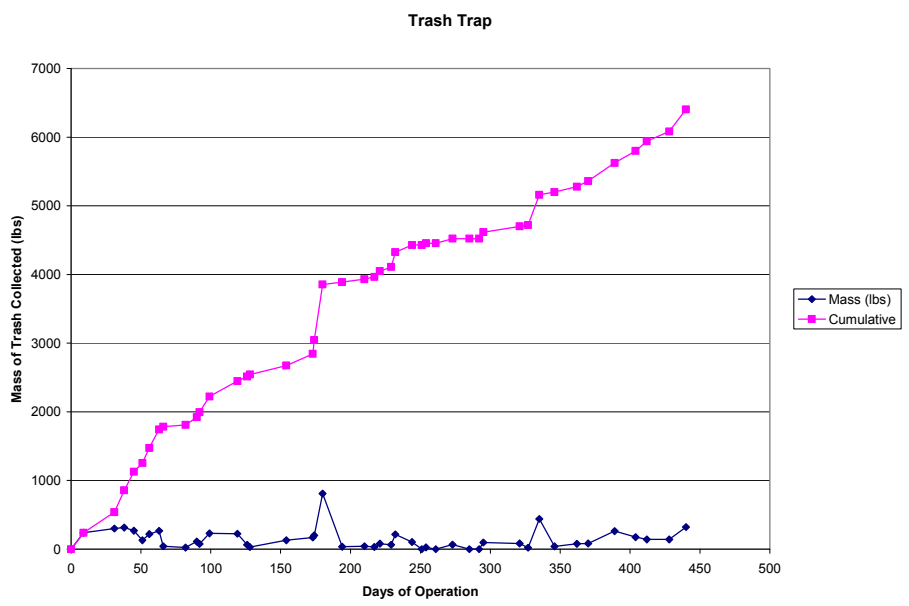

Figure 5: Total weights of trash removed from the Bandalong trash trap.

At times during the course of this project, both designs of screens suffered from apparent vandalism problems or durability of the screens for a given catch basin. Trident screens or glass screens that were installed on catch basins over 
190 inches long sometimes failed under the pressure of water and the weakness in the middle of the screen. Implementation of a plan that included catch basin screens would have to include repair of screens as a part of a regular maintenance program.

\section{Conclusions}

The three trash removal techniques evaluated in this study were: a Bandalong Trash Trap installed by Stormwater Systems, an inlet screen manufactured by Trident Solutions, and an inlet screen designed by Dr. Charles Glass. From the data presented throughout this report it is our conclusion that the general order of performance based on cost effectiveness in descending order were: the inlet screen designed by Dr. Glass, the Bandalong, and finally the Trident Solutions screens.

Additional recommendations include: 1) all screens and the Bandalong should be cleared of trash after rain events. For the screens the maintenance after rain events mitigates the fear of traffic collisions caused by ponding water in front of clogged catch basins (by clearing the screens every two weeks we witness no evidence of ponding as Los Angeles did in an earlier study with less frequent maintenance). For the Bandalong clearing after rain events mitigates the escape of fugitive trash. This requirement will result in more frequent maintenance during rainy seasons and less during dry spells. 2) Street sweeping, if implemented, would mitigate the removal of trash by hand and lower the load of trash and sediment that becomes bound in the spaces of the screens. 3) Inlet screens are the most inexpensive alternative for improved performance; however decentralized technologies require focused operation and maintenance.

\section{References}

[1] United States Environmental Protection Agency. 1996. Stormwater Technology Fact Sheet: Water Quality Inlets, EPA, Office of Water, Washington DC.

[2] Lee, J. H., Bang, K.W., Ketchum, L.H., Choe, J.S., and M.J. Yu., First Flush Analysis of Urban Storm runoff. The Science of the Total Environment, 293, pp. 163-175, 2002.

[3] Field, R., Combined Sewer Overflows: Control and Treatment (Chapter 4). Control and Treatment of Combined Sewer Overflows, ed. P.E. Moffa Van Nostrand Reinhold, New York, pp. 151-237, 1990.

[4] Lager, J., W. Smith, R. Finn, and E. Finnemore. Urban Stormwater Management and Technology: Update and Users' Guide, 1977.

[5] United States Environmental Protection Agency. 1987. A compendium of Superfund Field Operations Methods, Office of Emergency and Remedial Response, Washington, D.C.

[6] Minnesota Pollution Control Agency, 1989. Protecting Water Quality in Urban Areas, Division of Water Quality, MPCA, MN. 
[7] Total Maximum Daily Loads of Trash for the Anacostia River Watershed, Montgomery and Prince George's Counties, Maryland and the District of Columbia, Maryland Department of Environment and District of Columbia Department of Environment - Natural Resources Administration http://www.mde.state.md.us/assets/document/Anacostia_Trash_TMDL_PN .pdf

[8] Aronson, G., D. Watson, and W. Pisaro. 1983. Evaluation of Catch Basin Performance for Urban Stormwater Pollution Control. United States Environmental Protection Agency, Washington, DC.

[9] Michigan Department of Enviromental Quality, 1992. http://www.michigan.gov/documents/deq/deq-wb-nps-cab_250605_7.pdf

[10] USEPA Storm water O and M Fact Sheet Catch Basin Cleaning, Office of Water, Washington, D.C. 1999.

[11] Harper, D. and Hollister, J., 2008, Personal Communication, C.C. Glass. Visited several demonstration sites in White Oak, MD. 